widened. It frequently happens that the portion at middle heights is not visible, on account of the relative dryness of the air.

F. J. W. Whipple (Meteorological Magazine, February I922), writing on cloud pendants, shows that within a whirl of 20 metres diameter, rotating once in a second, with a lowering of pressure of $30 \mathrm{mb}$. at the centre, the maximum wind speed would be 70 metres per second, or 160 miles per hour, in agreement with winds estimated in tornadoes. A deficiency of $30 \mathrm{mb}$. pressure represents a suction sufficient to support $\mathrm{I}$ foot of water only. The solid appearance of a waterspout is therefore not to be ascribed to the lifting up into the air of a solid column of water, but is due partly to the condensation of water vapour within the whirl itself, and partly to water drops which are carried upward in spiral paths. This upward motion of water drops is a well-marked feature of most waterspouts.

The existence of an outer sheath, separated from the central core by a clear space, would appear to require a discontinuity of water content of the air, symmetrical about the axis of the whirl. It does not appear possible to explain it even as the effect of discontinuities of velocity within the whirl. No physical explanation of this clear space can be suggested.

It is usuany suggested in text-books (for example, Humphreys's "Physics of the Air," p. 213) that waterspouts are formed at the boundaries of wind currents of different directions. But as such boundaries are of considerable extent, it is difficult to understand why single waterspouts ever come into existence. One would rather expect to find large families of waterspouts distributed over a considerable area. It is true that usually several are seen at the same time, but isolated cases are not infrequent.

The fact that Dr. Hale Carpenter, while standing within about one hundred yards of the waterspout he describes, apparently felt no wind from the whirl, testifies to the very limited diameter of the whirl in question.

wieteorological Office, Air Ministry,

D. BRUNT. Sept. I.

\section{Periodic Structure of Atoms and Elements.}

A. C. CReHORE, in his recent papers on "The Hydrogen Molecule" in the Philosophical Magazine (October I92I, May I922, and June I922), makes use of the specially constituted atoms of hydrogen and helium discussed by him, and of a hypothetical atom, the atomic weight of which is $2 \frac{1}{3}$, to build up some of the other atoms. He uses $\mathrm{H}$ particles, hydrogen with charge $+e$; $a$-particles, helium with charge $+2 e$; and particles of his hypothetical element, with positive charge $+e$. I think it is clear that he recognises the need for a helium particle with positive charge $+e$ in addition, if neutral atoms are to be built up in the way he indicates. In one of his models one of the particles marked 4 is also marked with a dot, and this evidently means that it has a charge $+e$ only. Calling these particles $\gamma$, glucinum or beryllium becomes $a$, $\gamma, \mathrm{H}$ and its structure appears to be $\gamma{ }^{\alpha}-\mathrm{H}$, where the hyphens indicate electrons. Its isotope, of atomic weight $\mathrm{I} 2$, is $-\gamma-\mathrm{H}-\gamma-\mathrm{H}$..., forming a simple ring of unit-charged particles. Nitrogen is $2 \alpha, \gamma, 2 \mathrm{H}$, and may have the structure

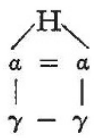

Fluorine, instead of having the constitution assigned to it by Crehore, may be $2 \alpha, 2 \gamma, 3 \mathrm{H}$, and may have either of the two following structures:

$$
=a^{-\gamma-\mathrm{H}-\mathrm{H}-}-\alpha:: \text { : }
$$

the $\alpha$ 's joining up to form a ring, or

$$
-\gamma-\mathrm{H}-\left.\right|_{-\gamma-a} ^{-\mathrm{H}} \mid \ldots
$$

the two $\gamma$ 's joining up to the $a$ on the right to form a ring.

Starting from the element of lowest atomic weight in each of the groups of the periodic table, I have found it possible to build up all the other elements of these groups, with atoms of distinctly similar structure for each group, and marked differentiation between the different groups. This has already been carried out up to uranium for nearly all the groups, so that hypothetical models, of the correct atomic weight and atomic number, could now be constructed for the majority, and probably for all, of the known elements and their actual and probable isotopes. Uranium (U.I.) has been assigned the structure

$$
={ }^{{ }_{1} 5^{\alpha}}-7 \gamma-{ }^{\mathrm{I}} 5^{\alpha}-7 \gamma-\mathrm{H}-{ }^{\alpha}-7 \gamma-\mathrm{H}-{ }^{-}
$$

forming a ring-shaped chain of thirty-one $\alpha$-particles joined up by two equal chains of $7 \gamma$ particles and two other equal chains of $7 \gamma$ and one $\mathrm{H}$ particle. This type of structure may be assigned to elements of Group VI.

H. NEWMaN ALLEN.

3 Lexham Gardens, Kensington, W.8, Aug. 26.

\section{Transmission of Sound of Explosions.}

REaders of Nature may be interested to know that a Commission appointed a year ago for investigating the transmission of sound of explosions is arranging for an experiment on this subject to take place on a day to be notified as soon after September 23 as the veather will permit.

On this occasion it is the War-Minister of the Netherlands who has been able to assist the Commission by notifying it of the intention to explode, in the day to be appointed, some ro,ooo kilogrammes of perchlorate of ammonium at 19.30 (western European time) ; the main explosion will be preceded by a small explosion of a mass of 500 kilogrammes at 10.25 .

I learn these particulars from Prof. Van Everdingen, director of the Meteorological Service of the Netherlands, who tells me that the countries surrounding the locus of explosion-Oldebroek, Lat. $52^{\circ} 29^{\prime} 56^{\prime \prime} \mathrm{N}$., Long. $5^{\circ} 59^{\prime} 40^{\prime \prime} \mathrm{E}$.- -within 500 kilometres, are being invited to instruct their observers to watch for evidence of the explosion.

Sept. $x 8$.

Napier Shaw

\section{Research and Razors.}

THE incident referred to by Principai Irvine (NATURE, Sept. 16, p. 385) may have been in connexion with Faraday's work on special steels. These were not, I think, a success so far as their use for razors is concerned, so that the present was appropriate. In any case Faraday had little to complain of, since the modern manufacturer does not send even razors.

J. R. Partington.

45 Kensington Gardens Square, W.2. Sept. I6. 